\title{
Diagnosis of Lyme borreliosis: non-specific serological reactions with Borrelia burgdorferi sonicate antigen caused by $\lg \mathrm{G} 2$ antibodies
}

\author{
I. J. T. SEPPÄLÄ, R. KRONELD*, K. SCHAUMAN, K.-O. FORSEN† and R. LASSENIUS $\ddagger$
}

Department of Bacteriology and Immunology, PO Box 21 (Haartmanin-katu 3), FIN-00014 University of Helsinki, * Department of Statistics, Åbo Academy and Åbolands Hospital, 20700 Turku, † Mjölbolsta Hospital, 10350 Mjölbolsta, Finland and $\ddagger$ Västerås Hospital, 80350 Västeràs, Sweden

\begin{abstract}
Summary. ELISA methods that measure IgG class antibodies to sonicated Borrelia burgdorferi may give false positive results. These errors could be traced to non-specific reactivity in subclass $\mathrm{IgG} 2$ in several instances. Sera were sampled randomly from two adult populations, which differed in having a high and low incidence of Lyme disease. If the binding of IgG2 subclass antibodies was left unrecorded in the test by the use of monoclonal reagent antibodies selective for IgG1 and IgG3, the frequency of positivity in the ELISA test decreased in samples from the low risk group. Twenty-one samples were found to be positive in an immunoblot confirmatory test. Correct prediction of positivity was obtained for 15 sera by ELISA restricted to IgG1 plus IgG3, for only four sera by ELISA restricted to IgG2 and for only six sera by IgG subclass non-restricted ELISA. A non-restricted ELISA with purified flagella of $B$. burgdorferi as the antigen predicted correctly 14 of the immunoblot-positive sera. The results of this ELISA correlated well with those of the IgG1 plus IgG3 subclass restricted ELISA in the high risk population $(\mathrm{r}=0.95$, prevalence of seropositivity $12 \%)$, but was significantly worse for the low risk group $(\mathrm{r}=0.47$, prevalence $2 \cdot 9 \%)$. IgG subclass restriction also decreased cross-reactions of syphilitic sera in the ELISA with sonicated antigen.
\end{abstract}

\section{Introduction}

The diagnosis of infections caused by Borrelia burgdorferi (sensu lato ${ }^{1}$ ), is complicated by considerable difficulty in culturing the organism and by the unsatisfactory sensitivity and specificity of serological diagnosis. ${ }^{23}$ The serological tests suffer from inconsistencies in precision and reproducibility, and from lack of concordance with the clinical evaluation of the patient, especially if whole bacteria or crude antigen fractions are used as the antigens. Improved assays have been formulated with semi-purified ${ }^{4}$ or purified antigens such as flagella ${ }^{5,6}$ or other proteins $(83$ or $39 \mathrm{kDa}) .{ }^{7.8}$ Purification of antigenic components from these sparsely growing bacteria is expensive.

Improved specificity is needed for the present antibody assays with whole $B$. burgdorferi bacteria. The specific IgG antibody response to $B$. burgdorfer $i$ is reported to consist of the IgG1 and IgG3 subclasses, whereas antibodies of the IgG2 subclass were found to cross-react with Treponema phagedenis. ${ }^{9} \mathrm{IgG} 2$ subclass immunoglobulins contain most of the antibody activity against several polysaccharide antigens and their production appears to require CD8-positive T cells. ${ }^{10}$ The aim of the present study was to evaluate the relevance of IgG subclasses in antibody testing for diagnostic purposes. Because of confusion caused by IgG2 subclass antibodies in these tests, the effect of the exclusion of IgG2 subclass antibodies from the serological test was analysed with a sonicate of whole bacteria as the antigen and subclass-specific developing antibodies. These tests are also compared with an ELISA with endoflagellar antigen and with antibody patterns detected by immunoblotting. The assays were evaluated with sera collected from two populations with different incidences of Lyme borreliosis.

\section{Materials and methods}

\section{Patient sera}

Sera from patients in various health service organisations in Finland were referred for routine evaluation of antibodies to $B$. burgdorferi. Clinical data were provided either along with the referral or retrospectively from selected patients.

Forty-two sera from patients with syphilis were selected from samples referred for serological evaluation. The criteria for inclusion in this collection was a positive TPHA test (Fujirebio Inc., Tokyo, Japan) as well as a positive result in either the VDRL test or the 
TmpA antibody test ${ }^{11}$ (Medscand Diagnostics, Malmö, Sweden).

\section{Sera from high and low risk populations}

Group I (high risk). Sera were obtained randomly from the adult population of a rural island community (Iniö) in the Baltic Sea in the southwestern archipelago of Finland. Minor chronic illness did not lead to exclusion from the study. The region comprises numerous small islands, mostly rocky, but partly covered with thick scrub. This archipelago is known to be a high risk area for exposure to Ixodes ricinus carrying B. burgdorferi..$^{12,13}$ The incidence of Lyme borreliosis has been 160 cases $/ 10^{5}$ inhabitants/year in the neighbouring Åland district (P. Wahlberg, personal communication); $80 \%$ of patients remember having been bitten by ticks and $16 \%$ had recognised skin manifestations associated with tick bites. ${ }^{14}$ Furthermore, the tick-borne Kumlinge arbovirus, which can cause encephalitis, is endemic in the islands. ${ }^{15}$ The community on the islands is stable, with few new settlers joining the population. Sera were collected from 149 inhabitants, who constituted $65 \%$ of the adult population.

Group II (low risk). Sera were received from 239 apparently healthy persons, living in an area with a low incidence of Lyme borreliosis, the Jyväskylä district in Central Finland. The population was mainly urban and sera were provided by DrO. Meurman. The incidence of the disease is low, perhaps because of the cold winter climate and subsequent poor survival of the animal carriers of B. burgdorferi. Ticks, as well as the diseases transmitted by them, also tend to be relatively infrequent in the district. Clinical Lyme borreliosis is at least 10 -fold less common than on the archipelago.

For the last decades the annual incidence of syphilis in Finland has varied between $0 \cdot 2$ and $0 \cdot 8 / 10^{5}$ inhabitants; both regions involved in the study have a below average incidence. Therefore, exposure to $T$. pallidum is unlikely to affect the results.

\section{B. burgdorferi strain}

A spirochaete strain KS1 of subgroup VS461 according to $16 \mathrm{~S}$ rRNA sequence ${ }^{16}$ was cultured from a skin biopsy sample of a patient with erythema migrans in BSK medium ${ }^{17}$ modified by substituting rabbit serum with fetal calf serum. The patient lived in a town in southern Finland but was a frequent visitor to the archipelago on the southwestern coast of Finland. The isolate was examined by Dr Kari Hovind-Hougen, National Veterinary Laboratory, Denmark, by electronmicroscopy and showed close structural identity to known Scandinavian B. burgdorferi strains.

To provide antigen, the isolate was grown in BSK medium for 3 weeks. After confirmation of purity of the culture, the bacteria were collected by centrifug- ation and washed four times with phosphate-buffered saline (PBS). The bacteria were sonicated until the turbidity was cleared. The sonicate was then centrifuged at $11000 \mathrm{~g}$ for $10 \mathrm{~min}$. The supernate was collected and its optical density (OD) was measured at $280 \mathrm{~nm}$. A dilution was calculated that would give an OD value of $0 \cdot 005$. Every second column on a microtitration plate was coated with the antigen diluted to this concentration with PBS, and left overnight at $4^{\circ} \mathrm{C}$.

\section{Enzyme immunoassay for antibodies to the sonicated antigen (ELISA-S)}

The coated plates (see above) were washed with saline containing Tween $200.01 \%$. Sera were diluted in bovine gelatin $5 \mathrm{mg} / \mathrm{ml}$ in PBS plus Tween 20 $0.01 \%$ (GTPBS) from 1 in 100 to 1 in 72000 in threefold steps and applied to the wells in two parallel columns, one with the antigen, the other without, serving as a control for non-specific binding. After overnight incubation, the plates were washed four times as above and a monoclonal antibody (MAb) to human immunoglobulin was added. This varied in the experiments as indicated in the text. Ascitic fluids containing the following antibodies were obtained locally: HP6070 anti-IgG1, 2F5 anti-IgG3, 2D6 antihuman IgG, ${ }^{18} 1 \mathrm{C} 2$ anti-IgG4, ${ }^{19}$ and HP6014 anti$\mathrm{IgG} 2$ (clone donated by $\mathrm{C}$. Reimer). The ascitic fluids were diluted 1 in 3000 in GTPBS (except 2F5, which was diluted 1 in 5000). HP6070 was used after purification of the IgG1 fraction by protein ASepharose (Pharmacia, Sweden), $3 \mu \mathrm{g} / \mathrm{ml}$ in TGPBS. The MAb was incubated overnight in the wells, the plate was washed, and biotin-labelled goat anti-mouse IgG (Zymed; 1 in 3000 in GTPBS) was added and incubated overnight. After washing, alkaline phosphatase-labelled streptavidin (Dakopatts; 1 in 3000 in GTPBS) was added. The plates were incubated overnight, washed, and the phosphatase activity was measured with 4-nitrophenylphosphate disodium salt $2 \mathrm{mg} / \mathrm{ml}$ in diethanolamine- $\mathrm{MgCl}_{2}$ buffer, $\mathrm{pH} 10 \cdot 0$ (Orion, Finland). $\mathrm{OD}_{405}$ values were measured, the blank value of reagents without serum was subtracted, and the value for non-specific binding at the particular serum dilution was subtracted from the value of the corresponding antigen-positive well. An end-point titre was obtained, usually at an $\mathrm{OD}_{405}$ of 0.40 ; the computer program ELISA Plus (Meddata Inc., New York, USA) was used for data processing. Inter-assay variation was controlled by a small adjustment of the OD reading level to obtain standardised values from two control sera, one representing a moderately positive sample and the other a sample of weak positivity, both run in duplicate. The upper borderline titre of normal values was initially set as 1000 in the IgG-ELISA-S test by comparison of results from 1800 patient samples referred for $B$. burgdorferi antibody testing by a reference method. ${ }^{20}$ The diagnostic cut-off levels were re-evaluated as described in the text. 
Determination of IgG antibodies to the endoflagella of B. burgdorferi (ELISA-F)

Commercial flagellar antigen-coated plates (Dakopatts, Denmark) were used according to the manufacturer's instructions, except that antibodies were titrated as described below. Serial three-fold dilutions of samples were incubated in the antigen-coated plates for at least $3 \mathrm{~h}$ at room temperature with constant rocking. The plates were washed, peroxidase-labelled anti-human IgG was added and the enzyme reaction was developed according to the manufacturer's instructions. The assay was calibrated by the cut-off control of the kit. This has an antibody content corresponding to a level that is exceeded by $2 \%$ of healthy Danish and Swedish populations (information given with the kit). This control material was taken to represent a serum of borderline positivity at a predilution of 1 in 200 , since this is the recommended dilution for patient sera. Two dilutions of this cut-off control were used, undiluted and a dilution of 1 in 3 corresponding to estimated dilution factors of 200 and 600 , respectively, from the hypothetical control serum. For reading end-point titres, an $\mathrm{OD}_{492}$ was chosen, which gave an interpolated dilution value of 500 for the cut-off control. This choice allowed the use of an approximately similar data expression scale at the upper border of normal values as was used in a reference assay. ${ }^{20}$ We did not aim for similarity at other levels.

\section{Assay for IgG subclass-resolved antibodies to the endoflagella of $B$. burgdorferi}

The antigen-coated strips of the kit described above were used. Sera were diluted serially in GTPBS and incubated in the strips overnight. After washing, MAbs to the human subclasses were added as above except that NL16 (Oxoid) was used at dilution of 1 in 3000 for IgG1. The assays for total IgG antibodies and for IgGl subclass antibodies were calibrated with the cut-off control as described above, on the assumption that the majority of the antibody activity would be in IgG1. For IgG2, IgG3 and IgG4, no suitable standards were available; therefore, the titre values are not necessarily comparable to those of IgG and of IgG1. On the basis of previous work with these MAbs, the scales are known not to differ by more than three times from each other. ${ }^{21}$

\section{Immunoblotting}

B. burgdorferi strain SK 1 cells were electrophoresed in SDS-polyacrylamide 7-13\% gradient gels with Mighty Small apparatus (Hoefer). A semi-dry transfer of proteins to nitrocellulose was done with Trisglycine-SDS $0.037 \%$-methanol $20 \%$ buffer by a $24 \mathrm{~V} / \mathrm{cm}$ electric field. Blocking and washing were with Tween $200.01 \%$ in $0.15 \mathrm{M} \mathrm{NaCl}$. Five $\mathrm{ml}$ of a 1 in 250 dilution of serum were incubated overnight with a strip. The reactions were developed by incubation with rabbit anti-human IgG (1 in 2000; Dakopatts) and with alkaline phosphatase-conjugated swine anti-rabbit immunoglobulin (1 in 250; Orion Diagnostica, Espoo, Finland). In IgG subclass-resolved immunoblots, the developing reagents were the same as described for the corresponding ELISA-S assays, except that a mixture of HP6014 and HP6008 MAb ascitic fluids (Oxoid; both at a final dilution of 1 in 3000) was used for IgG2 development. The substrate was $60 \mu \mathrm{M}$ 5-bromo-4-chloro-3-indolyl-phosphate $p$ toluidine salt and $80 \mu \mathrm{M}$ nitroblue tetrazolium in $50 \mathrm{mM} \mathrm{KHCO}_{3}$ plus $1 \mathrm{mM} \mathrm{MgCl}_{2}$. The band intensities were given scores by visual inspection according to the following rules: 0 , no band or a barely visible band; 1 , a narrow faint band; 2 , a narrow moderately stained band; 3 , a slightly broadened darkly stained band; 4 , a moderately broadened darkly stained band; 5 , a greatly broadened maximally stained band.

In the immunoblot analyses, a positive result was reported if an 83-kDa band was associated with a 41$\mathrm{kDa}$ band with an intensity score of at least two, or any other band with a score of three, or if a 41-kDa band of an intensity score of three or more was associated with a band with a score of at least three at 31-, 34-, 37or 48-kDa. An indecisive blot was reported if a single 83- or 41-kDa band with an intensity score of two was observed. Negative immunoblots were recorded if no band had an intensity over one, or if other patterns than those mentioned above were observed.

\section{Results}

To analyse the specificity of IgG subclass restricted assays for $B$. burgdorferi antibodies, ELISAs for antibodies in IgG1 combined with IgG3 (complement fixing subclasses), in IgG2 and IgG4 (separately) and in whole $\operatorname{IgG}$ were developed. The antigen was a sonicate of $B$. burgdorferi (ELISA-S). The results were compared to an IgG ELISA with $B$. burgdorferi flagella as the antigen (ELISA-F). The distribution of titres for the ELISAs was evaluated with randomly collected sera from high risk (group I) and low risk (group II) populations (fig. 1).

The cut-off level for the IgG-ELISA-S test was reevaluated by analysis of the titres of the random population sera. Sera with definite antibody positivity in the statistical analysis of the cut-off limits were excluded first, because normality, in the sense of absence of encounter with an unusual microbe, cannot be ensured if the population has a demonstrable prevalence of the infection. This task is difficult because of the lack of absolute standards. Immunoblot analyses were performed on all samples that were positive in any of the IgG-S, IgG1 +3-S or -F ELISAs. Sera were considered to be antibody positive if confirmed by immunoblotting, or if the results of these three ELISA types were all clearly positive. Such samples were excluded from the material in the 

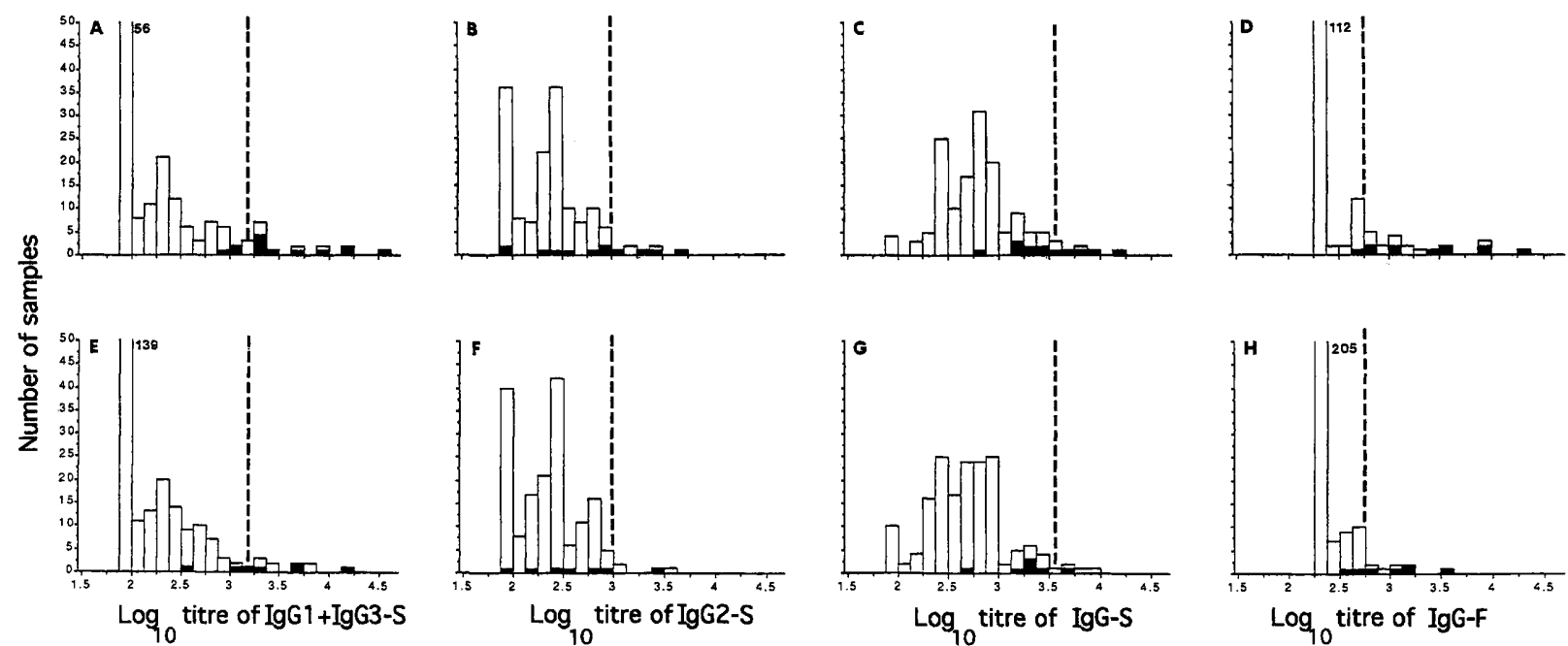

Fig. 1. Distribution of ELISA titres in randomly collected sera. The abscissas indicate $\log _{10}$ transformed titres of the tests, the ordinates the number of samples. The bars open at the top indicate a number of samples exceeding the ordinate scale and the number is indicated. Figs. A, B, C and D are for group I samples, figs. E, F, G and $\mathrm{H}$ for group II. Titres that remained below the measurable range were assigned values of 99 in the ELISA-S and 199 in the ELISA-F. $\square$, immunoblot positive samples; the vertical broken lines indicate cut-off limits.

Table I. ELISA titres and immunoblot scores for selected sera from population groups I and II

\begin{tabular}{|c|c|c|c|c|c|c|c|c|c|c|c|c|}
\hline \multirow{2}{*}{ Sample no. } & \multicolumn{8}{|c|}{ ELISA type*, titres } & \multicolumn{4}{|c|}{ Immunoblot score for antigen of } \\
\hline & IgG-F & IgG1-F & IgG2-F & IgG3-F & IgG4-F & IgG-S & IgG2-S & $\mathrm{IgG} 1+3-\mathrm{S}$ & $83 \mathrm{kDa}$ & $66 \mathrm{kDa}$ & $41 \mathrm{kDa}$ & $37 \mathrm{kDa}$ \\
\hline \multicolumn{13}{|l|}{ Group I } \\
\hline 1 & 8400 & 7500 & 560 & 300 & 1600 & 16000 & 2500 & 15000 & 2 & 0 & 5 & 3 \\
\hline 2 & 3600 & 510 & 430 & 300 & 700 & 900 & 600 & 1300 & 0 & 1 & 4 & 0 \\
\hline 3 & 3300 & 2700 & 560 & 250 & 900 & 3200 & 560 & 4500 & 2 & 2 & 1 & 4 \\
\hline 4 & 3100 & 1300 & 180 & $<100$ & $<100$ & 1600 & 220 & 1800 & 1 & 0 & 4 & 0 \\
\hline 5 & 1500 & 1100 & 100 & $<100$ & $<100$ & 870 & 270 & 900 & - & - & - & - \\
\hline 6 & 790 & 550 & 120 & $<100$ & $<100$ & $<100$ & 250 & 780 & 2 & 2 & 5 & 0 \\
\hline 7 & 750 & 310 & $<100$ & $<100$ & $<100$ & 560 & 250 & 380 & 0 & 2 & 0 & 1 \\
\hline 8 & 620 & 840 & $<100$ & $<100$ & 470 & 800 & 300 & 2100 & 1 & 2 & 1 & 1 \\
\hline 9 & 590 & 860 & $<100$ & $<100$ & $<100$ & 1600 & $<100$ & 1700 & 2 & 1 & 5 & 0 \\
\hline 10 & 550 & 840 & $<100$ & $<100$ & 470 & 1200 & 300 & 1900 & 1 & 0 & 0 & 0 \\
\hline 11 & 520 & 220 & $<100$ & $<100$ & $<100$ & 850 & 270 & 220 & 0 & 2 & 0 & 0 \\
\hline 12 & 480 & 340 & 110 & $<100$ & $<100$ & 1900 & $<100$ & 1000 & 1 & 1 & 3 & 0 \\
\hline 13 & 450 & 650 & 120 & $<100$ & $<100$ & 330 & 180 & 200 & 0 & 2 & 0 & 5 \\
\hline 14 & 450 & 200 & 130 & $<100$ & $<100$ & 580 & 230 & 270 & 0 & 1 & 0 & 0 \\
\hline 15 & 450 & 340 & $<100$ & $<100$ & $<100$ & 590 & 250 & 320 & 0 & 1 & 0 & 1 \\
\hline 16 & 350 & $<200$ & $<100$ & $<100$ & 300 & 790 & 300 & 120 & 0 & 2 & 0 & $i$ \\
\hline 17 & 300 & $<200$ & $<100$ & 260 & 300 & 1500 & 860 & 230 & 1 & 1 & 1 & 0 \\
\hline 18 & $<200$ & $<200$ & $<100$ & $<100$ & $<100$ & 260 & 140 & $<100$ & 0 & 1 & 0 & 0 \\
\hline 19 & $<200$ & - & - & - & - & 3500 & 1100 & 150 & 1 & 0 & 0 & 0 \\
\hline \multicolumn{13}{|l|}{ Group II } \\
\hline 20 & 4200 & 520 & 210 & 200 & 300 & 1800 & 1900 & 4800 & 2 & 1 & 2 & 0 \\
\hline 21 & 1600 & 1000 & 480 & $<100$ & $<100$ & 1500 & 590 & 730 & 0 & 1 & 5 & 0 \\
\hline 22 & 1400 & 2800 & 2200 & 170 & $<100$ & 4400 & 710 & 14000 & 3 & 1 & 3 & 3 \\
\hline 23 & 1200 & 1200 & $<100$ & $<100$ & $<100$ & 1500 & 330 & 2300 & 1 & 1 & 4 & 1 \\
\hline 24 & 1100 & 400 & $<100$ & $<100$ & 140 & 2500 & 290 & 1300 & 2 & 1 & 2 & 2 \\
\hline 25 & 840 & 1500 & 150 & $<100$ & $<100$ & 630 & 260 & $<100$ & 0 & 1 & 1 & 2 \\
\hline 26 & 550 & 490 & 900 & $<100$ & $<100$ & 1800 & 530 & 1700 & 1 & 1 & 5 & 0 \\
\hline 27 & 530 & 350 & 270 & $<100$ & $<100$ & 590 & 160 & $<100$ & 0 & 1 & 1 & 0 \\
\hline 28 & 520 & 570 & 150 & $<100$ & $<100$ & 2400 & 3200 & 2600 & 0 & 5 & 0 & 0 \\
\hline 29 & 510 & $<200$ & $<100$ & $<100$ & $<100$ & 350 & $<100$ & 480 & - & - & - & - \\
\hline 30 & 460 & 410 & $<100$ & $<100$ & $<100$ & 8000 & $<100$ & $<300$ & 0 & 1 & 0 & 0 \\
\hline 31 & 450 & $<200$ & $<100$ & $<100$ & $<100$ & 470 & $<100$ & 450 & 1 & 1 & 3 & 0 \\
\hline 32 & 380 & $<200$ & $<100$ & $<100$ & $<100$ & 520 & 130 & 280 & 0 & 1 & 1 & 0 \\
\hline 33 & 370 & $<200$ & 170 & $<100$ & $<100$ & 1900 & 690 & 510 & 1 & 0 & 0 & 1 \\
\hline 34 & 360 & $<200$ & $<100$ & $<100$ & $<100$ & 4500 & 2700 & $<100$ & 0 & 1 & 2 & 0 \\
\hline 35 & 320 & 260 & $<100$ & $<100$ & $<100$ & 3400 & 1100 & 280 & 0 & 1 & 0 & 0 \\
\hline 36 & 430 & - & - & - & - & 2300 & 250 & 730 & 0 & 2 & 4 & 0 \\
\hline 37 & $<200$ & - & - & - & - & - & 210 & 2300 . & 0 & 3 & 0 & 2 \\
\hline 38 & 310 & - & - & - & - & 1700 & 270 & 6800 & 0 & 1 & 1 & 2 \\
\hline 39 & $<200$ & - & - & - & - & 2400 & 700 & $<100$ & 0 & 1 & 0 & 1 \\
\hline 40 & $<200$ & - & - & - & - & 7400 & 290 & 6200 & 0 & 0 & 0 & 0 \\
\hline 41 & 670 & - & - & - & - & 2200 & 160 & 4500 & 3 & 1 & 5 & 1 \\
\hline 42 & 510 & - & - & - & - & 2300 & 330 & 2700 & 1 & 1 & 0 & 0 \\
\hline 43 & 590 & - & - & - & - & 2300 & 1300 & 380 & 0 & 2 & 2 & 0 \\
\hline 44 & $<200$ & - & - & - & - & 2300 & 140 & 970 & 0 & 3 & 0 & 0 \\
\hline
\end{tabular}

Of group I, samples are presented for which IgG subclass titres were measured, and one apparently false positive sample (no. 19). Of group II, all samples positive in any ELISA are shown.

* F, flagellar antigen; $\mathrm{S}$, sonicate antigen. 
Table II. Correlations of ELISA tests for B. burgdorferi antibodies

\begin{tabular}{llrlll}
\hline \multicolumn{1}{c}{ Compared tests } & & Group & $\mathrm{N}$ & $\mathrm{r}$ & $\mathrm{p}^{*}$ \\
\hline IgG1+ IgG3-S versus & IgG-S & I & 146 & 0.770 & - \\
IgG1 + IgG3-S & IgG-S & II & 180 & 0.517 & - \\
IgG1 + IgG3-S & IgG-F & I & 148 & 0.949 & $<0.0005$ \\
IgG1 + IgG3-S & IgG-F & II & 239 & 0.473 & $<0.30$ \\
IgG1 + IgG3-S & IgG2-S & I & 147 & 0.752 & $<0.40$ \\
IgG1+ IgG3-S & IgG2-S & II & 180 & 0.216 & $<0.0025$ \\
IgG-S versus & IgG-F & I & 147 & 0.748 & $<0.35$ \\
IgG-S & IgG-F & II & 180 & 0.259 & $<0.0025$ \\
IgG-S & IgG2-S & I & 147 & 0.752 & $<0.40$ \\
IgG-S & IgG2-S & II & 149 & 0.405 & $<0.15$ \\
IgG2-S versus & IgG-F & I & 149 & 0.786 & $<0.40$ \\
IgG2-S & IgG-F & II & 180 & 0.372 & $<0.05$ \\
& & & & & \\
\hline
\end{tabular}

$\mathrm{N}$, number of determination pairs, $\mathrm{r}$, correlation coefficient of the method pair. ${ }^{*} p$, value for comparison of the $r$ value of the method pair on that line to the $r$ value of the pair of IgG1 + IgG3-S and IgG$\mathrm{S}$ tests within the population group indicated. All comparisons of the method pairs in group I to the corresponding pair in group II gave values of $\mathrm{p}<0 \cdot 0005$. All $\mathrm{r}$ values differed significantly from zero $(\mathrm{p}<0.0025)$.

calculation of cut-off limits. Thus data were obtained showing that seven samples of the low disease incidence group II could be excluded (including nos. 20, $22,23,24,26$ and 41, table I). Thereafter we could obtain the cut-off limits (fig. 1).

When the samples from the high frequency area for Lyme disease (group I) were similarly analysed by immunoblotting and ELISAs for exclusion from a "normal collection" 18 samples gave positive results. For analysis of the resolving power of the ELISAs the positive samples were retained in this population. Correlation coefficients were calculated for the ELISA assays (table II). All correlations within group I were significantly better than within group II ( $p<0.001, \mathrm{z}$ transformation and $t$ test). This points to a lack of specificity of low grade positive results in a population of low disease incidence. The values of the $\operatorname{IgG} 1+3$ ELISA-S correlated very well with ELISA-F values in group I $(r=0.949)$, but significantly worse with IgGELISA-S values. This probably indicates a better performance of IgG1 + 3-ELISA-S and ELISA-F than of the IgG-ELISA-S.

The titres of the IgG2-ELISA-S correlated weakly with the other ELISA values, still having better correlation to IgG-ELISA-S within group I than within group II (table II). Only weak correlations were seen with IgG1 + 3-ELISA-S or to ELISA-F.

An apparent discrepancy was that IgG2 antibodies were often non-specific with sonicated bacteria, whereas with the flagellar antigen no subclass restriction seemed to be necessary. This may have been because a relatively small proportion of $\mathrm{IgG} 2$ subclass immunoglobulins were directed towards the flagellar protein antigen or because the IgG2 antibodies directed to this antigen were mostly truly specific. To analyse this, three sets of sera from the population sample were selected. One set consisted of apparently positive samples, one of borderline samples and the third of antibody negative samples. An IgG subclass-resoived test was performed with the flagellar antigen. For population group I, IgG1 and total IgG antibodies showed a good correlation in 18 samples (table I). When positive, the IgG2 flagellar antibody titres correlated with positivity in IgG1 antibodies, i.e., in definitely immune cases. The titres with the various subclass specific antibodies are not comparable, but still show a low amount of IgG2 antibodies in the negative and the doubtful serum groups. Two sera from group II in this selection (nos. 34 and 35) had IgG2 and IgG antibodies to the sonicate antigen, but no IgG2 antibodies to the flagella, nor IgG1 or IgG3 antibodies to the sonicated antigen. IgG3 and IgG4 antibodies to the flagella could be found only in association with IgG1 subclass antibodies. Probably the antibodies of IgG3 and IgG4

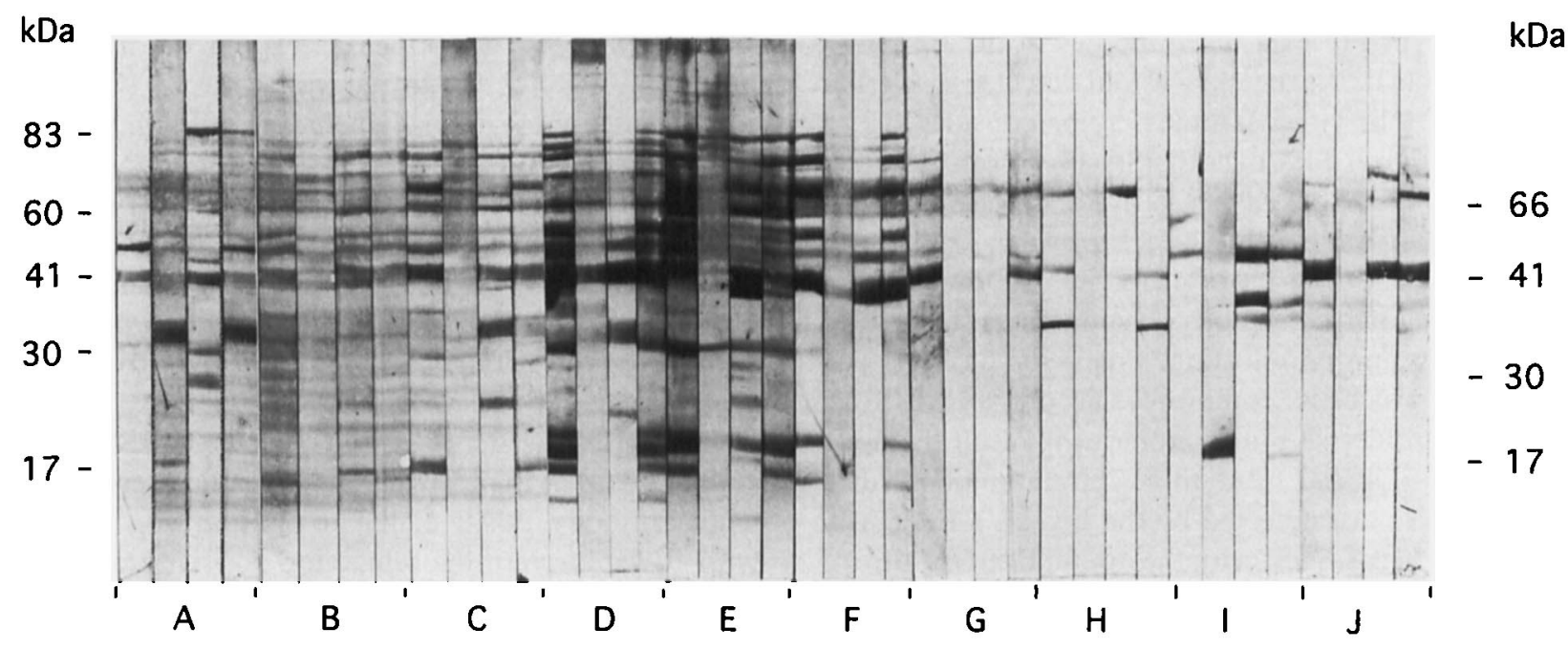

Fig. 2. IgG subclass resolved immunoblotting. The immunoblots were performed with $B$. burgdorferi strain SK1. Panels A, B, C, were obtained with sera nos. 19,35 and 43 of table I; D, E, F : sera from patients with clinically typical third-stage Lyme borreliosis; G: serum from a healthy volunteer; H, I, J: syphilis patients. In each panel of four strips, the developing reagents were specific (from left to right) for IgG1, IgG2, IgG3 and total IgG. The mol. wt scale on the left refers to panels A-F, and the scale on the right to panels $\mathrm{G}-\mathrm{J}$. 
Table III. Immunoblot results in the Lyme disease high prevalence population (group I)

\begin{tabular}{|c|c|c|c|c|c|c|}
\hline \multirow{2}{*}{ ELISA type } & \multirow{2}{*}{ ELISA result } & \multicolumn{5}{|c|}{ Number of samples that gave immunoblot result } \\
\hline & & positive & indecisive & negative & not done & total \\
\hline IgG-F & + & 11 & 7 & 7 & 3 & 28 \\
\hline IgG-F & - & 2 & 6 & 17 & 96 & 121 \\
\hline IgG1 + IgG3-S & + & 10 & 3 & 4 & 1 & 18 \\
\hline IgG1 + IgG3-S & - & 3 & 10 & 20 & 98 & 131 \\
\hline $\operatorname{IgG} 2-S$ & + & 4 & 2 & 1 & 0 & 7 \\
\hline IgG2-S & - & 9 & 11 & 24 & 98 & 142 \\
\hline IgG-S “ sensitive”* & + & 12 & 4 & 8 & 2 & 26 \\
\hline IgG-S "sensitive" & - & 1 & 9 & 16 & 95 & 121 \\
\hline IgG-S "nominal" $\dagger$ & + & 5 & 2 & 0 & 3 & 10 \\
\hline IgG-S "nominal" & - & 8 & 11 & 24 & 94 & 137 \\
\hline
\end{tabular}

The data include four indecisive and seven negative immunoblot results from sera for which no ELISA assay was positive. For the other samples, at least one ELISA result was positive or doubtful.

* A cut-off value of 1500 was used to have a more sensitive assay despite some loss of specificity.

$\dagger$ A cut-off value of 3200 was used according to the distribution of values in group II.

subclasses were a minority of the total IgG antibody, because in modified immunoblots, only a few bands could be developed with these restrictions (fig. 2, data not shown for IgG4).

Fifty samples from group I were studied by immunoblotting. These included 39 samples that had given any suspected positive ELISA result (inclusion titre $>$ 1000 in any sonicate antigen test, titre $>500$ for flagellar antigen; table III). Low sample volume precluded study of three samples. Eleven samples were studied as ELISA-negative controls. None of them gave positive immunoblotting results, four gave undecisive or equivocal blots. Of the ELISA-positive or suspected positive samples, 13 were positive by immunoblotting, 11 gave indecisive immunoblotting results and 15 gave negative results. Only two positive results were obtained by immunoblotting in association with a negative ELISA-F result. Both gave positive results in the IgG1 + 3-ELISA-S, one with just below the cut-off level of antibodies in the ELISA-F (no. 12; table I), the second without detectable flagellar antibodies. The latter sample may be considered as a definite failure for the ELISA-F. Seven samples positive by ELISA-F gave negative results by immunoblotting, indicating either a lack of specificity in this ELISA or, perhaps, more probably, the difficulty to correctly classify antibody responses restricted to flagellin by immunoblotting. Positivity of $\operatorname{IgG} 1+3$ ELISA-S was less commonly accompanied by a negative or indecisive immunoblotting result than was a positive ELISA-F, but three immunoblot positive samples were not detected by the IgG1+3-ELISA-S. The IgG-ELISA-S test with the nominal cut-off titre of 3200 was specific but insensitive. A more sensitive reading at a cut-off of 1500 led to similar sensitivity as that for the ELISA-F. Of the 12 samples considered to be negative or indecisive by immunoblotting, despite a positive sensitively read IgG-ELISA-S, only two gave positive results in IgG1 + 3-ELISA-S. Therefore, apparently at least one-third of the positive results with the IgG-ELISA-S were false positive, as no other test could confirm the positivity. Positivity by IgG2ELISA-S did not predict positivity by immunoblotting.

Immunoblotting was performed on 12 ELISA-F negative samples from group II (table I). One sample gave a score of four for the 41-kDa band, together with a positive IgG-ELISA-S, and was probably truly antibody positive. Of the two samples with a suspicious positivity in IgG2-ELISA-S, one was negative by immunoblotting and the other gave indecisive results (nos. 34 and 35; table I).

The prevalences of antibody positivity in the population groups were analysed by combining test results. Population group I had $12 \%$ prevalence for definite immunity to $B$. burgdorferi (ELISA-F $>1000$ or immunoblot positive, or both, if available; a few samples were used up before testing by immunoblotting). Only $2.9 \%$ of group II were definitely positive with those criteria. Including borderline positivity (41-kDa score of at least two by immunoblotting or, if immunoblotting was not performed, ELISA-F $>500$ ), the incidences were $22 \%$ and $5.7 \%$, respectively, for the two populations. In group I, the mean age of antibody-negative persons was 46 years, and that of the strongly antibody-positive individuals was 64 years.

Group II showed $5.4 \%$ positivity with ELISA-F. As seven $(2.9 \%)$ of the 239 samples were considered to be truly antibody positive due to immunising contact with $B$. burgdorferi, the remaining positivity could be due to the statistical distribution of values in a normal population. In addition to four clearly immune persons, the IgG1 + 3-ELISA-S test was positive in four others who were marginally positive in ELISA-F (nos. 26, 28, 41 and 42; table I). Of the latter samples, 
Table IV. ELISA titres in clinically confirmed Lyme borreliosis patients

\begin{tabular}{|c|c|c|c|c|c|c|c|}
\hline \multirow{2}{*}{ Patient no. } & \multirow{2}{*}{ Age (years) } & \multirow{2}{*}{$\begin{array}{c}\text { Time } \\
\text { interval } \\
\text { (months) }\end{array}$} & \multirow{2}{*}{ Disease } & \multicolumn{4}{|c|}{ ELISA titre } \\
\hline & & & & $\operatorname{IgG} 1+3-\mathrm{S}$ & IgG2-S & IgG-S & IgG-F \\
\hline 1 & 39 & $0 \cdot 7$ & $\mathrm{Neu}$ & $<200$ & 210 & 540 & 310 \\
\hline 1 & & 1.6 & & $<200$ & 220 & 500 & 360 \\
\hline 1 & & 6 & $<200$ & $<200$ & $<200$ & 410 & 590 \\
\hline 1 & & 12 & & 200 & 250 & 470 & 700 \\
\hline 2 & 26 & 0 & Neu† & 4300 & 2100 & 6000 & 4600 \\
\hline 2 & & 0.7 & & 4200 & 2400 & 5800 & 6700 \\
\hline 2 & & $3 \cdot 5$ & & 4700 & 2400 & 5800 & 5300 \\
\hline 3 & 54 & $1 \cdot 5$ & $\mathrm{Neu}$ & 3100 & $<200$ & 2000 & 1800 \\
\hline 3 & & 4 & & 910 & $<200$ & 760 & 850 \\
\hline 4 & 4 & 1 & EM & $<200$ & 320 & 590 & 530 \\
\hline 4 & & 2 & & $<200$ & 300 & 500 & 770 \\
\hline 5 & 31 & 2 & EM & $<200$ & $<200$ & 230 & 540 \\
\hline 6 & 67 & 24 & EM, Unsp. & 2500 & $<200$ & 1200 & 1900 \\
\hline 7 & 81 & 48 & EM, Neuf & 4900 & 1000 & 2600 & 2400 \\
\hline 8 & 5 & 26 & EM, Unsp. & 8700 & 8200 & 5900 & 4900 \\
\hline 9 & 37 & 3 & TB, Art & $<200$ & 5400 & 1600 & 1400 \\
\hline 10 & 42 & 6 & TB, Art & $<200$ & 250 & 550 & 440 \\
\hline 11 & 36 & 2 & TB, Unsp. & $<200$ & 1400 & 1000 & 1000 \\
\hline 11 & & 3 & & 460 & 1500 & 1700 & 2400 \\
\hline 11 & & 4 & & 720 & 1600 & 1800 & 1600 \\
\hline
\end{tabular}

* Art, arthritis; EM, erythema migrans; Neu, neurological symptoms; TB, tick bite; Unsp., non-specific symptoms.

$\dagger$ Recurrent neurological symptoms after a latent period of 3 years in treated neuroborreliosis.

$\ddagger$ Non-compliance in the treatment of EM.

Table V. Cross-reactivity of Lyme borreliosis serology in patients with positive syphilis serology*

\begin{tabular}{lrrrr}
\hline \multirow{2}{*}{$\begin{array}{c}\text { Titre } \\
\text { category }\end{array}$} & \multicolumn{4}{c}{$\begin{array}{c}\text { Number of samples with given } \\
\text { category in ELISA type }\end{array}$} \\
\cline { 2 - 5 } & IgG1+ IgG3-S & IgG-S & IgG2-S & IgG-F \\
\hline$<0.25$ & 12 & 6 & 7 & - \\
$0 \cdot 25-0.50$ & 3 & 5 & 2 & 33 \\
$0.51-1 \cdot 00$ & 1 & 0 & 2 & 3 \\
$1 \cdot 01-2 \cdot 00$ & 0 & 3 & 2 & 1 \\
$>2 \cdot 00$ & 0 & 2 & 3 & 2 \\
Cut-off titre used $\dagger$ & 1500 & 1500 & 1000 & 500 \\
& & & &
\end{tabular}

* Positive TPHA reaction in all sera, geometric mean VDRL titre was 9.5.

$\dagger$ The level assigned as the upper border of normal values was used as the cut-off titre. The titres obtained from individual sera were divided by the cut-off titre and the result assigned to the categories. Category values above one represent a positive assay result, values below one are in the normal range. For the IgG-S test a cut-off level of 1500 was chosen that would have assured detection of most of the immunoblot positive samples in fig. 2 as the cut-off level calculated from the normal persons was too high to correctly identify samples of antibody positivity in the immunoblot.

two were positive by immunoblotting. However, three positive results in the IgG1 +3-ELISA-S test could not be confirmed by either immunoblotting or ELISA$F$ tests (nos. 37, 38 and 40 ). Thus, the error frequency of IgG1 + 3-ELISA-S seems to be similar to that of ELISA-F.

A limited series of experiments was performed to analyse the restriction of immunoblotting reactivity to IgG subclasses. Immunoblot reactions were developed by reagents specific to IgG1, IgG2, IgG3 or total IgG. Generally, development for IgG2 revealed less intense bands than were observed for the other subclasses or for total IgG (fig. 2). This was not due to technical weakness in the IgG2 immunoblotting, as a band restricted to IgG2 subclass was also seen at the expected strength in the total IgG strip (frame A; fig. 2). IgG1 and IgG3 could bind separate antigens. As expected, because of the dominance of IgG1 in serum immunoglobulins, most of the IgG bands resembled the pattern observed for IgG1. Yet when the subclass was restricted, the banding patterns had a better contrast to the background than in unrestricted immunoblotting. Further studies are necessary for analysis of the predictive value of subclass restricted bands.

The subclasses of antibodies were also analysed in a collection of clinically clear Lyme borreliosis patients (table IV). Several patients had positive IgG2-S ELISA results but others lacked it. IgG2 antibody was earlier than $\operatorname{IgG} 1+3$ antibodies present in two cases, but the pre-disease level remains unknown. Antibody positivity in IgG-F ELISA consistently preceded positivity in the IgG1 + 3-S ELISA in early Lyme borreliosis.

Sera from patients with syphilis were used to study the specificity of these tests. IgG1 + 3-ELISA-S was not positive in any of 16 sera, whereas IgG-ELISA-S and especially IgG2-ELISA-S were cross-reactive (table V). ELISA-F was positive in three of 39 syphilitic sera. Immunoblots of 21 of these sera showed highly variable staining patterns with, sometimes, even strong staining of 41-, 60-, 66- and 74-kDa bands (fig. 2 ). The $83-\mathrm{kDa}$ protein was stained by none of these sera. 


\section{Discussion}

The results suggest that antibodies of the $\mathrm{IgG} 2$ subclass binding to $B$. burgdorferi can, depending on the case, be cross-reactive or specific. They may also be induced by immunogens other than B. burgdorferi, provided that the microbes have sufficiently similar antigenic epitopes. Such cross-reactive immunity could also be primed originally by other bacteria but the antibody level could be enhanced by contact with $B$. burgdorferi. Non-pathogenic spirochaetes can provide a cross-reactive stimulus ${ }^{9,22-24}$ but demonstration of one source of cross-reactive antigens does not exclude the role of others.

Immunoblotting with anti-IgG2 reagents mostly failed to reveal prominent antigens responsible for the reactivity. As IgG2 subclass immunoglobulins seem to be directed to carbohydrate antigens to a large extent, ${ }^{10}$ the immunoblot strips may not have immobilised the relevant antigens, or they may have had variable mol. wts. Like Olsson et al. ${ }^{25}$ we could demonstrate the presence of IgG2 antibodies to the flagellar antigen in samples that were also positive for IgG1 antibodies by ELISA. Thus the IgG 2 antibodies observed with the sonicate antigen may belong to a different subpopulation that is not specific to diagnostically useful antigens.

Borreliae share with practically all bacteria an antigen of $c .60 \mathrm{kDa}$ which is a heat shock protein. ${ }^{26}$ There was a strong $60-\mathrm{kDa}$ band with IgG2 antibodies in the serial samples of one patient who had false positive results by ELISA-S. Three of 18 syphilitic patients had IgG1 antibodies to this antigen. However, the immunoblot scores of IgG antibodies to 60-66$\mathrm{kDa}$ antigens had no general correlation with any of the titres measured in this work (data not shown).

Restriction of the reagents to detect only IgGl and IgG3 widened the titre range obtainable with the sonicate antigen compared with the values obtained with anti-total IgG, indicating improved discrimination of positive values from negative values. Immunoblotting was negative in four of $17 \mathrm{IgG} 1+3$ ELISA-S positive sera and in eight of 24 IgG-ELISA$S$ positive sera of group I. This is in agreement with the finding that tests based on complement fixation have superior specificity over ordinary ELISA or IFA tests, ${ }^{2,27}$ as IgG1 and IgG3 subclass antibodies fix complement well but IgG2 fixes it poorly. Similarly, IgG1 and IgG3 antibody subclasses have been shown to contain the majority of antibodies to T. pallidum in syphilis. ${ }^{28}$ Good specificity is reported for a diagnostic bactericidal test. ${ }^{29}$ The antibodies operative in the test probably belong to IgG1 or IgG3 subclasses.

The endoflagellar antigen of $B$. burgdorferi appeared to be useful for diagnostic purposes, confirming previous observations. ${ }^{5,30}$ To improve grading of high flagellar antibody values end-point titres were measured, unlike previous studies that recorded absorbances. This could explain the rarity, in our measurements, of significant cross-reactions mediated by anti- treponemal antibodies. Titres $>2000$ are typical in late Lyme borreliosis. ${ }^{31}$ Early disease could be diagnosed better by measuring the antibodies to the flagellum than by IgG1 + 3 ELISA-S (table IV). This may be for several reasons. There is a slow process operating in lymph nodes to generate high avidity IgG1 antibody-forming B cells. ${ }^{32}$ This process is probably fastest in the case of quantitatively major antigens such as the flagellum. Furthermore, the sharing of epitopes of the flagellum with other bacteria could mean pre-existing helper T-cell immunity to this antigen, speeding up the antibody responses but perhaps increasing the danger of cross-reactivity in diagnostic work. The specificity of any early immune response to $B$. burgdorferi-except the affinity maturation process-should probably be judged with caution.

None of the ELISA-F positive results could be claimed to be definite false positives, although immunoblot analysis did not always confirm the positivity. An immune response directed to the flagellum only could not in fact have given a positive immunoblotting result by the positivity criteria applied. Lack of follow-up samples prevented evaluation of these discrepancies. In contrast, at least one third of the IgG-ELISA-S positive results appeared to be false positive, if sufficient sensitivity was maintained. Therefore, the IgG-ELISA-S seems to be useful only as a screening test in conjunction with a more specific confirmatory test. This conclusion is consistent with recent results of an analogous survey in USA ${ }^{33}$ where immunofluorescent or ELISA assays could not predict immunoblot positivity. The subclass or antigenrestricted assays in the present study both had a better predictive power.

Variable criteria have been used in the evaluation of immunoblotting for positivity. Mere positive band counts as a criterion of positivity should not be used, ${ }^{34-35}$ as several antigens have structurally related counterparts in other bacteria. Thus, only specific bands should be evaluated, such as the $39-$ and $83-\mathrm{kDa}$ bands. ${ }^{7-8}$ An $83-\mathrm{kDa}$ band has been the most specific indicator of Lyme borreliosis in referred samples from patients from the highly endemic Åland archipelago by our immunoblotting method (data not shown). Bands of 17, 19, 21, 31 and $48 \mathrm{kDa}$ also appear useful. Interpretation of the $41-\mathrm{kDa}$ bands of flagellin was problematic. The intensity scores of the $41-\mathrm{kDa}$ bands had a weak correlation with the 83-kDa bands $(r=$ $0 \cdot 48$ ), but a better correlation with ELISA-F in group I $(\mathrm{r}=0.65)$. Strong $41-\mathrm{kDa}$ bands are seen in clinically apparent Lyme borreliosis but low intensity bands are frequent in normal controls. Three of 21 sera from syphilitic patients gave strong $41-\mathrm{kDa}$ bands by immunoblotting. Therefore, this band cannot alone be considered sufficient to indicate a positive test. ${ }^{36}$ Together with another, more specific band such as 83 or $31 \mathrm{kDa}$, a strong band of $41 \mathrm{kDa}$ was considered to be indicative of a positive result. Bands of 60 and $66 \mathrm{kDa}$ showed an apparent lack of specificity. The 39- 
$\mathrm{kDa}$ band could not be evaluated in these experiments, as our VS461 group strain lacked the $39-\mathrm{kDa}$ band, although our method was able to discern it on bacteria of strain B31 (data not shown). Recently reported criteria for immunoblot positivity ${ }^{36}$ clearly did not fully apply to our antigen. Generally, our immunoblotting method was approximately as sensitive as the ELISAs for detection of antibody positivity. The use of a biotin-streptavidin amplification system may have been critical for sensitivity.

The specificity of $B$. burgdorferi antibody assays that rely on flagellar antigen has been questioned because of structural homologies and cross-reactivities among the flagella of several bacteria. ${ }^{37}$ This question was addressed by studying 35 sera with high antibody titres to various antigens, including the flagella of salmonellae, by the ELISA-F test. Only one sample gave clearly positive results and two samples gave borderline values. Thus, no major lack of specificity could be observed. Avoidance of exposure of the determinants located at the ends of the flagellin protein in the ELISA antigen appears to be critical for the specificity of the test. ${ }^{38}$ Opening of the tertiary structure of the flagellum, e.g., by SDS, appears to be undesirable.

The prevalence of antibody positivity in the Iniö archipelago was similar to that reported for the Swedish islands of Lisö. Also the prevalence of positivity in a Swedish low risk area was similar to our evaluation..$^{13}$ As in Sweden, antibody prevalence to $B$. burgdorferi increased with age in the Finnish populations. Seropositivity to tick-borne encephalitis arbovirus (Kumlinge virus) was not correlated with immunity to B. burgdorferi.

The technical assistance of Ms Pirkko Kokkonen is gratefully acknowledged. We thank Dr Olli Meurman for sera from population II and Dr Matti Kaartinen for $16 \mathrm{~S}$ rRNA sequence analysis of our B. burgdorferi strain.

\section{References}

1. Baranton G, Postic D, Saint Girons I et al. Delineation of Borrelia burgdorferi sensu stricto, Borrelia garinii sp. nov., and group VS461 associated with Lyme borreliosis. Int $J$ Syst Bacteriol 1992; 42: 378-383.

2. Lane RS, Lennette ET, Madigan JE. Interlaboratory and intralaboratory comparisons of indirect immunofluorescence assays for serodiagnosis of Lyme disease. $J$ Clin Microbiol 1990; 28: 1774-1779.

3. Golightly MG, Thomas JA. Lyme borreliosis serologies in perspective. Clin Immunol Newsletter 1991; 11: 113-118.

4. Magnarelli LA, Anderson JF, Barbour AG. Enzyme-linked immunosorbent assays for Lyme disease: reactivity of subunits of Borrelia burgdorferi. J Infect Dis 1989; 159: 43-49.

5. Hansen K, Hindersson P, Strandberg Pedersen N. Measurement of antibodies to the Borrelia burgdorferi flagellum improves serodiagnosis in Lyme disease. J Clin Microbiol 1988; 26: 338-346.

6. Coleman JL, Benach JL. Identification and characterization of an endoflagellar antigen of Borrelia burgdorferi. J Clin Invest $1989 ; 84$ : 322-330.

7. Lefebvre RB, Perng GC, Johnson RC. The 83-kilodalton antigen of Borrelia burgdorferi which stimulates immunoglobulin $\mathrm{M}(\mathrm{IgM})$ and IgG responses in infected hosts is expressed by a chromosomal gene. J Clin Microbiol 1990; 28: 1673-1675.

8. Simpson WJ, Burgdorfer W, Schrumpf ME, Karstens RH, Schwan TG. Antibody to a 39-kilodalton Borrelia burgdorferi antigen (P39) as a marker for infection in experimentally and naturally infected animals. J Clin Microbiol 1991: 29: 236-243.

9. Hechemy KE, Harris HL, Duerr MJ, Benach JL, Reimer CB. Immunoglobulin $\mathrm{G}$ subclasses specific to Borrelia burgdorferi in patients with Lyme disease. Ann NY Acad Sci 1988; 539: 162-169.

10. Regueiro JR, Perez-Aciego P, Aparicio P, Martinez C, Morales $\mathrm{P}$, Arnaiz-Villena A. Low IgG2 and polysaccharide response in a $\mathrm{T}$ cell receptor expression defect. Eur J Immunol 1990; 20: $2411-2416$.

11. Ijsselmuiden OE, Schouls LM, Stolz E et al. Sensitivity and specificity of an enzyme-linked immunosorbent assay using the recombinant DNA-derived Treponema pallidum protein TmpA for serodiagnosis of syphilis and the potential use of TmpA for assessing the effect of antibiotic therapy. J Clin Microbiol 1989; 27: 152-157.

12. Schauman K, Kovanen J, Seppälä I. Lyme borreliosis in Finland 1986-1988. Biomed Pharmacother 1989; 43: $427-430$.

13. Gustafson R, Svenungsson B, Gardulf A, Stiernstedt G, Forsgren $M$. Prevalence of tick-borne encephalitis and Lyme borreliosis in a defined Swedish population. Scand $J$ Infect Dis 1990; 22: 297-306.

14. Wahlberg P. Incidence of tick-bite in man in Åland islands: reference to the spread of Lyme borreliosis. Scand J Infect Dis $1990 ; 22$ : 59-62.

15. Kroneld R, Meurman O, Forsen K-O, Lassenius R. The prevalence of antibodies against viruses causing Kumlinge and Pogosta diseases on the islands of Iniö on the southwest coast of Finland. Scand J Infect Dis 1989; 21 : 9-13.

16. Marconi RT, Garon CF. Development of polymerase chain reaction primer sets for diagnosis of Lyme disease and for species-specific identification of Lyme disease isolates by 16S rRNA signature nucleotide analysis. $J$ Clin Microbiol 1992; 30: 2830-2834

17. Berger BW, Kaplan MH, Rothenberg IR, Barbour AG Isolation and characterization of the Lyme disease spirochete from the skin of patients with erythema chronicum migrans. J Am Acad Dermatol 1985; 13: 444-449.

18. Sarnesto A. Monoclonal antibodies reacting with isotypic and/or allotypic determinants of human IgG. Med Biol $1983 ; 61: 126-132$.

19. Seppälä I, Sarvas H, Mäkelä O, Mattila P, Eskola J, Käyhty H. Human antibody responses to two conjugate vaccines of Haemophilus influenzae type b saccharides and diphtheria toxin. Scand J Immunol 1988; 28: 471-479.

20. Stiernstedt GT, Granström M, Hederstedt B, Sköldenberg B. Diagnosis of spirochetal meningitis by enzyme-linked immunosorbent assay and indirect immunofluorescence assay in serum and cerebrospinal fluid. J Clin Microbiol 1985; 21 : 819-825.

21. Seppälä IJT, Routonen N, Sarnesto A, Mattila PA, Mäkelä O The percentages of six immunoglobulin isotypes in human antibodies to tetanus toxoid: standardization of isotypespecific second antibodies in solid-phase assay. Eur $J$ Immunol 1984; 14: 868-875.

22. Magnarelli LA, Anderson JF, Johnson RC. Cross-reactivity in serological tests for Lyme disease and other spirochetal infections. J Infect Dis 1987; 156: 183-188.

23. Raoult D, Hechemy KE, Baranton G. Cross-reaction with Borrelia burgdorferi antigen of sera from patients with human immunodeficiency virus infection, syphilis and leptospirosis. J Clin Microbiol 1989; 27: 2152-2155.

24. Magnarelli LA, Miller JN, Anderson JF, Riviere GR. Crossreactivity of nonspecific treponemal antibody in serologic tests for Lyme disease. J Clin Microbiol 1990; 28 $1276-1279$

25. Olsson I, Hammarström L, Smith CIE, Hovmark A, Åsbrink E 
IgG subclasses of specific antibodies in Ixodes ricinusborne borreliosis. Clin Exp Immunol 1987; 69: 618-623.

26. Hansen K, Bangsborg JM, Fjordvang H, Strandberg Pedersen $\mathrm{N}$, Hindersson $\mathrm{P}$. Immunochemical characterization of and isolation of the gene for a Borrelia burgdorferi immunodominant 60-kilodalton antigen common to a wide range of bacteria. Infect Immun 1988; 56: 2047-2053.

27. Artsob H, Huibner S. Complement fixation test for the diagnosis of Lyme disease. J Clin Microbiol 1990; 28 : 637-638.

28. Baughn RE, Jorizzo JL, Adams CB, Musher DM. Ig class and IgG subclass responses to Treponema pallidum in patients with syphilis. J Clin Immunol 1988; 8: 128-139.

29. Callister SM, Schell RF, Case KL, Lovrich SD, Day SP. Characterization of the borreliacidal antibody response to Borrelia burgdorferi in humans: a serodiagnostic test. $J$ Infect Dis 1993; 167: 158-164.

30. Karlsson M, Stiernstedt G, Granström M, Åsbrink E, Wretlind B. Comparison of flagellum and sonicate antigens for serological diagnosis of Lyme borreliosis. Eur $J$ Clin Microbiol Infect Dis 1990; 9: 169-177.

31. Wahlberg P, Granlund H, Nyman D, Panelius J, Seppälä I. Late Lyme borreliosis: epidemiology, diagnosis and clinical features. Ann Med 1993; 25 : 349-352.

32. Berek $\mathrm{C}, \mathrm{Ziegner} \mathrm{M}$. The maturation of the immune response. Immunol Today 1993; 14: 400-404.
33. Huycke MM, D'Alessio DD, Marx JJ. Prevalence of antibody to Borrelia burgdorferi by indirect fluorescent antibody assay, ELISA and Western immunoblot in healthy adults in Wisconsin and Arizona. $J$ Infect Dis 1992; 165: 1133-1137.

34. Zöller L, Burkard S, Schäfer H. Validity of Western immunoblot band patterns in the serodiagnosis of Lyme borreliosis. $J$ Clin Microbiol 1991; 29: 174-182

35. Karlsson M, Möllegård I, Stiernstedt G, Wretlind B. Comparison of Western blot and enzyme-linked immunosorbent assay for diagnosis of Lyme borreliosis. Eur J Clin Microbiol Infect Dis 1989; 8: 871-877.

36. Dressler F, Whalen JA, Reinhardt BN, Steere AC. Western blotting in the serodiagnosis of Lyme disease. $J$ Infect Dis 1993; 167: 392-400.

37. Rasiah C, Schiltz E, Reichert J, Vogt A. Purification and characterization of a tryptic peptide of Borrelia burgdorferi flagellin, which reduces cross-reactivity in immunoblots and ELISA. J Gen Microbiol 1992; 138: 147-154.

38. Robinson JM, Pilot-Matias TJ, Pratt SD, Patel CB, Bevirt TS, Hunt CJ. Analysis of the humoral response to the Flagellin protein of Borrelia burgdorferi: Cloning of regions capable of differentiating Lyme disease from syphilis. J Clin Microbiol 1993; 31 : 629-635. 